\title{
Design \& Analysis of a Multiple Cutting Hacksaw Automatic Machine
}

\author{
Hemant Singh Raghuwanshi \\ Research Scholar, Department of Mechanical Engineering, \\ Sagar Institute of Research and Technology-Excellence, Bhopal, Madhya Pradesh, India
}

\begin{abstract}
A hacksaw is a fine-toothed saw, mostly utilized in reason for cutting metal. Hacksaw can likewise be utilized to cut different materials for instance plastic material (PVC pipes and pipe installations) and wooden materials with them. There are two sort in particular, hand saw forms and fueled variants (control hacksaws). Practically every one of the hacksaws are hand saws with a C-formed edge that holds an edge under strain with the maintenance screw. Such hacksaws have a handle, normally made of a wooden grasp, with pins for appending a restricted expendable hacksaw sharp edge. The bleeding edge of a saw is either a serrated sharp edge like teethes. The casings have additionally arrangement for acclimating to oblige sharp edges having distinctive lengths. A screw or other system is utilized to put the slender edge under strain.
\end{abstract}

Keywords: Design, Hacksaw, Automation

\section{INTRODUCTION}

Power hacksaws are utilized to cut extensive segments of metal. Cutting of strong shafts or bars of in excess of fifteen millimeters dia is a hard with a typical hand held hacksaw. In this manner control hacksaw machine was concocted amid 1920s in the United States to do the troublesome and tedious work.

Programmed Saw Cutting undertaking is exceptionally helpful in the modern organizations. In modern organizations there is have to slice the metals and woods to various shape. By utilizing labor it takes commonly, and furthermore precision might be low. By utilizing this undertaking cutting activity is preformatted naturally. So it spares the time just as decreases the labor.

The precision additionally accomplished in this undertaking. This task is structured with microcontroller, Real time clock, Relay driver circuit alongside transfers, Keypad and Mechanical course of action.

Constant clock is the unique kind to IC coordinated circuit used to produce genuine planning signal. It is by and large called as RTC. Battery is in work in this IC. Despite the fact that control is turned OFF, it can keep up the planning signal. RTC sends the planning sign to microcontroller. Here the microcontroller may Atmel or PIC both are streak type reprogrammable microcontroller in which we have just modified. The arrangement of keys in the keypad is utilized to set the season of activity.

For a precedent on the off chance that you need to cut the material for a hour the planning is set in the microcontroller through the key awful. The microcontroller gets the planning signal from RTC, and actuates the transfer driver circuit for that specific timeframe.
The hand-off yield is straightforwardly associated mechanical game plan. This mechanical game plan is intended to be fit the distinctive hack saw, for example, inclining teeth, sharp teeth and so on. So the cutting task is performed for that specific timeframe. Toward the finish of the setting time, microcontrollers turn OFF the transfer so the cutting task is halted.

Through along these lines cutting activity is performed consequently. This power hacksaw machine appeared in figure 1 is considered as a programmed machine in light of the fact that the administrator need not be there to give the responding movement and descending power on the workpiece so as to cut it. When the administrator has nourished the work-piece till the required length in to the machine and begins the machine, at that point the machine will cut until the work-piece has been totally sliced in to two pieces.

The way that the administrator needs to nourish the workpiece to the required length in to the bad habit is one viewpoint that inspired us to mechanize the sustaining of work-piece consequently. Another angle is that after a pole has been cut for one time, the administrator needs to empty the work-piece and advance whatever remains of the workpiece to the required length over and over till the finish of the work-piece is come to

\subsection{Working Guideline Of Power Hacksaw}

A power hacksaw (or electric hacksaw) is a kind of hacksaw that is fueled either by its own electric engine or associated with a stationary motor. Most power hacksaws are stationary machines yet some convenient models do exist; the last mentioned (with edges) have been uprooted to some degree by responding saws, for example, the Sawzall, which acknowledge sharp edges with hacksaw teeth. Stationary models as a rule have an instrument to lift up the saw cutting edge on the arrival stroke and some have a coolant siphon to keep the saw sharp edge from overheating. 


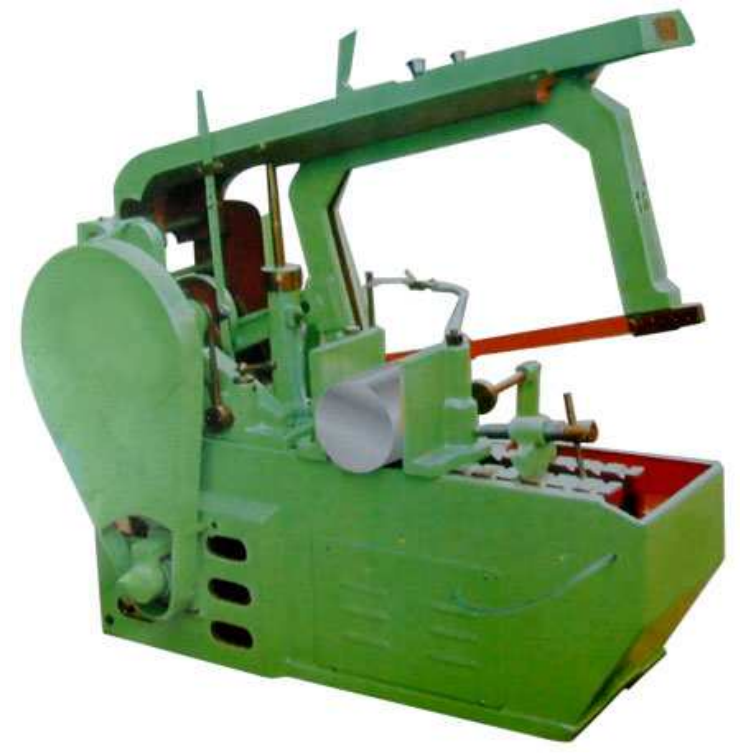

Fig1. Power Hacksaw Machine

Power hacksaws are not as generally utilized in the metalworking businesses as they used to be. Bandsaws and cold saws have for the most part dislodged them. While stationary electric hacksaws are not extremely normal, they are still created. Power hacksaws of the sort controlled by stationary motors and line shafts, as other line-shaft-fueled machines, are currently uncommon; historical centers and antique-device specialists still save a couple of them.

\subsection{Design Parameters:}

The most vital structure parameters that incite fabricating plant determination and setup included.

1. Creation necessities

2. Mineral uniqueness

3. Work scene

4. Working consultations

5. Creation capicity

6. Vital cast

7. Prosperity and foundation

8. Life of machine.

9. Defending necessities.

Focal points:

1. Expanded creation of various sizes at one time.

2. High level of item measure control.

3. Long existence of wear parts.

\section{LITERATURE REVIEW}

The target of this work is to robotize the regular power hacksaw machine so as to accomplish high profitability of work-pieces than the power hacksaw machine utilizing Microcontroller. The robotized machine gets two contributions from the client in particular the quantity of pieces to be cut and the length of each piece that is required to be cut. The administrator need not quantify the length of the work-piece that will be sliced and to stack and empty the work-piece from the toss each time after a piece has been cut. In the wake of getting the two contributions from the client, the machine consequently encourages the given length of work-piece in to a throw and begins to cut till the given number of work-pieces has been cut [1].

Hacksaw Machines offered by us are utilized for metal slicing running from transportable model to goliath measure machine. Attributable to smooth and rapid working capacities, these hacksaw machines tasks suddenly to help the laborer in reliably conveying his work with extreme skill [2].

In 2/4-year Engineering Technology and Industrial Technology programs. A broad cluster of modern applications is given to propel and animate understudies' enthusiasm for the field. It centers around the structure, examination, task, and support of liquid power frameworks. This book places accentuation on seeing how liquid power frameworks work and on their down to earth applications. A fundamental foundation in the field of liquid power is given, enabling understudies to comprehend the plan, investigation, task, and upkeep of liquid power frameworks [3].

Past examinations concerning the mechanics of the symmetrical metal cutting procedure have delivered connections between the different point parameters. These connections would he be able to used to anticipate the geometry of cutting or apparatus powers, and consequently are restricted in pertinence and helpfulness. The motivation behind the Investigation Is two-overlay; first to decide tentatively the impact of changes In the rake edge and cutting velocity on the kind of chip delivered amid symmetrical machining and after that to build up a summed up model of the symmetrical metal cutting process[4].

The impacts of a few procedure parameters, for example, grating and partition standard, on the outcomes are investigated. As reproduction device, business understood limited component. Partition of chip from the work piece is accomplished either just with nonstop retesting or by deleting components as indicated by the harm gathered. From the outcomes cutting and push powers, shear edge, chip thickness and contact length between the chip and the rake face of the instrument can be assessed [5].

The business accomplishment of another item is impacted when to showcase. Shorter item lead times are of significance in an aggressive market. This can be accomplished just if the item improvement procedure can be acknowledged in a generally little timeframe. New cutting supplements are produced by a tedious experimentation process guided by observational information of the metal cutting procedure. One of the best in class endeavors in assembling building is the limited component reenactment of the metal cutting procedure [6].

S. G. Bahaley, Dr. A. U. Awate, S. V. Saharkar [7] structured and manufactured a pedal controlled multipurpose machine. It is a human controlled machine wich is produced for lifting the water to a stature 10 meter and creates 14 Volt, 4 ampere of power in best way. Power required for accelerating is well underneath the limit of a normal sound person. The framework is likewise helpful for the work out reason in light of the fact that accelerating will go about as a wellbeing exercise and furthermore completing a valuable work.

Prof. Kshirsagar Prashant R [8] etal investigated on Theoretical Analysis of MultiWay Power Hacksaw Machine and reasoned that to beat issues in ordinary hacksaw machines, because of high productivity, simple to work and moderate value the proposed model of multi-way control hacksaw machine is useful and finishes every one of the desires required in the small ventures. Future extent of 
proposed research work to build the creation rate, cuts the metal bars effectively. It can withstand the vibrations, no dangers from jolt, no Special preparing required to work it.

Sreejith K. [9] etal examined on configuration, create and tentatively explore the working of Pedal Driven Hacksaw (PDH). PDH is taking a shot at Slider Crank Mechanism.

\section{OBJECTIVE AND METHODOLOGY}

Watch the normal marvels being referred to as they happen and if conceivable evaluate the perceptions: Primary cutting gear utilized in the total business is wasteful and overstructured. The correct choice and advancement of essential smashing hardware ought to be founded on the vitality required for shake breakage, the ideal item measure, and the ideal generation limit, which are all needy upon a legitimate physical portrayal of the stone being cut.

\section{Objective:-}

The Problem of intensity hacksaw machine is the nourishing of work-piece, which is dispensed with by including the numbers Hacksaw Frame which is separable so it will cut the bolstering time of work-piece and increment the no. of work piece to be cut, which coordinates the work-piece in to the seat shrewd. After this, a pneumatic seat savvy is reached out to hold the work-piece immovably to capture the development of work-pieces while being cut.

\section{Methodology:}

Strategy I am utilizing for its Design is Autodesk Inventor V2014 and for Stress Analysis I am utilizing Altair.

\section{Autodesk Inventor}

Autodesk Inventor is a CAD displaying programming, in which we can Design singular parts of any get together, we can likewise do Assembly and furthermore we can make Manufacturing Drawing/Production Ready Drawing. We can check Mechanical or Physical conduct of any segment or gathering by applying material and by doing dynamic recreation. I have utilized Autodesk Inventor Professional 2014 to plan staggered programmed power hacksaw machine.

Altair is a CAE programming in which we can do Pre and Post Analysis in this we need to produce great work, in this we have alternatives for making component $(1 d, 2 d$ and $3 d)$ according to prerequisite, we can likewise apply connectors. We have part numerous User Profile and alternatives for sending out our examination to some other investigation programming. Altair is the best CAE Software and it is anything but difficult to utilize/learn. I have utilized Altair Hypermesh V11.0 for Meshing and streamlining.

\section{Proposed Models view:}

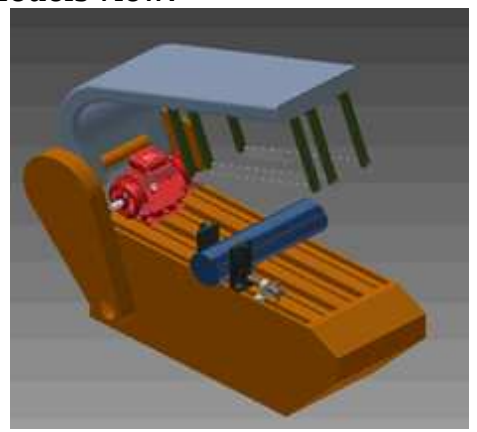

Fig.2 Proposed Models View DESIGN

\section{Base Frame}

Plan view of frame in support position. All pieces $3 / 4$ " $(19 \mathrm{~mm})$ steel angle.

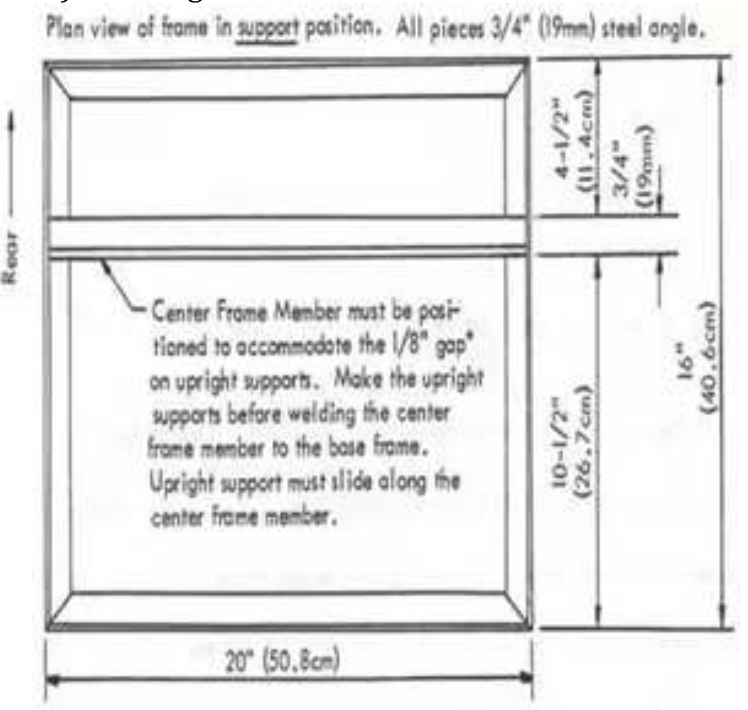

Fig3. Base Assembly

\section{Upright Supports}

Make two pieces of upright supports: one as shown and another one a reflection of the one shown below. All pieces are made of $3 / 4 "(19 \mathrm{~mm})$ steel angle, unless specified otherwise. Weld all joints.

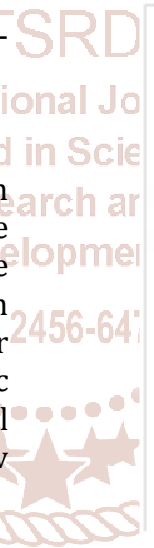

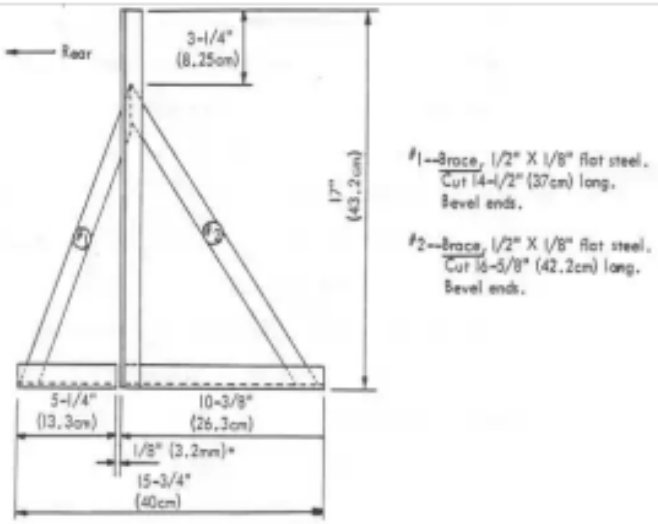

Fig4. Upright Support Assembly

\section{Design Considerations}

When planning our connection, the accompanying contemplations were considered

1. The gadget ought to be appropriate for neighborhood fabricating capacities.

2. The connection should utilize minimal effort materials and assembling techniques.

3. It ought to be available and moderate by low-salary gatherings, and ought to satisfy their essential requirement for mechanical power.

4. It ought to be easy to make, work, keep up and fix.

5. It ought to be as multi-reason as could be expected under the circumstances, giving capacity to different farming executes and for little machines utilized in rustic industry.

6. It should utilize locally accessible materials and abilities. Standard steel pieces, for example, steel plates, iron poles, point iron, and level stock that are locally accessible ought to be utilized. Standard instruments utilized in machine shop, for example, hack saw, records, punches, taps and kicks the bucket; medium obligation 
International Journal of Trend in Scientific Research and Development (IJTSRD) @ www.ijtsrd.com eISSN: 2456-6470

welder; drill press; little machine and processing machine ought to be sufficient to create the parts required.

7. Though the gadget ought to be anything but difficult to remove the parts, it is accepted that it would more often than not stay appended to encourage preparation and simplicity of transport from site to site. The gadget ought to almost certainly transmit capacity to an assortment of machines, and

\section{RESULT}

Amid the thesis work the Hack Saw Frame of the Hack Saw machine has been investigated to investigate the likelihood of utilizing an individual from the hacksaw machine itself as burden detecting part, this radically improves the hacksaw machine.

Burden estimation is an essential strategy empowering machine wellbeing observing and blame limitation, anyway direct estimation is generally troublesome or outlandish. The heap estimation is essential viewpoints in plan of machines and structures. The heap is essential parameter to plan the machines.

\section{FEM Analysis and Experiment}

The limited component examination did for hack saw machine part and the basic areas have been found. The component utilized for cross section was 4 hub tetra 287, Four hubs having four degrees of opportunity at every hub characterize the component, three interpretations in the nodal $\mathrm{x}, \mathrm{y}$, and $\mathrm{z}$ headings, and one hydrostatic weight (HDSP) for all materials and the material utilized was solid metal. The limit conditions utilized are, $\mathrm{z}$ bearing is settled at sharp edge focus, $\mathrm{x}$ course whenever settled on $U$ body. The material properties utilized are $\mathrm{E}=170 \mathrm{GPA}$, density $=400$ $\mathrm{kg} / \mathrm{m} 3$. The strain plot of the hack saw machine is appeared.

At the point when the cast iron was cut, the qualities are recorded and the chart is plotted. The LABVIEW yield window when the most extreme power was connected on the material is appeared in fig-6.2.The material will cut in the forward stroke of the machine. The most extreme strain will be in forward stroke. At the point when the more power is connected on the material to cut, in that circumstance the esteem will be greatest. We chose that a V-belt and pulley game plan would be most fitting for this. Belts don't require the exact arrangement that chains do. Belts can even suit pulleys that are marginally skewed as for one another. Changing drive proportions is as simple as evolving pulleys. Likewise, belts are sensibly effective.

The gadget ought to contain a tightening component that would give the administrator "a chance to coast" occasionally to rest and monitor vitality. The saws can be fitted with numerous embellishments, including snappy acting tight clamps, control stock feed, control bracing of work, and programmed cycling of the cutting task. The last moves the work out the required separation, braces it, and makes the cut naturally. The cycle is endless supply of the cut. Rapid cutting requires utilization of a coolant. Coolant decreases grating, expands cutting edge life, and avoids chipstopped up teeth. Cast iron and some metal compounds, in contrast to most materials, don't require coolant changing drive proportions ought to be as straightforward as could be expected under the Fully automatic power hacksaw machine
Table 1 Cost of fabrication

\begin{tabular}{|c|c|c|}
\hline Component & Quantity & Cost in Rs. \\
\hline Base with Chuck & 1 & 7,000 \\
\hline Frame & 1 & 6,500 \\
\hline D.C. Motor & 1 & 3,500 \\
\hline A.C. Motor & 1 & 2,500 \\
\hline Pneumatic cylinder & 1 & 2,500 \\
\hline Pneumatic DCV & 1 & 1,200 \\
\hline Hacksaw Blade & 3 & 450 \\
\hline Solenoid Valve & 1 & 650 \\
\hline Limit Switch & 1 & 350 \\
\hline Display, Keypad & 1 each & 1,200 \\
\hline Microcontroller & 1 & 800 \\
\hline IR Sensor & 1 & 1200 \\
\hline \multicolumn{2}{|l|}{ Total Cost } & 27,850 \\
\hline
\end{tabular}

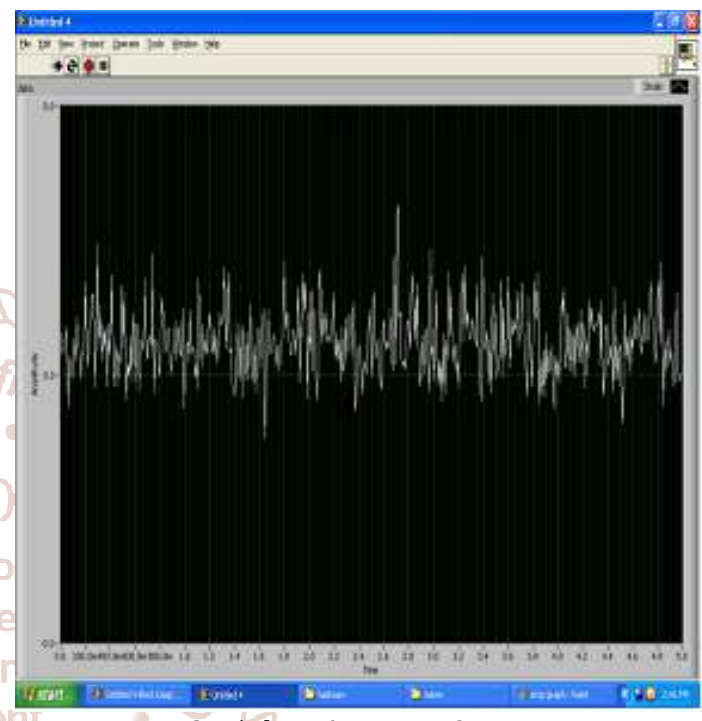

Fig.5 the LABVIEW Output

The quantities of qualities are recorded from lab see programming. These qualities are taken and the most extreme strain estimation of the machine was taken by plotting the diagram. The most extreme pinnacle an incentive for cast iron is $\mathbf{5 9}$ smaller scale strains.

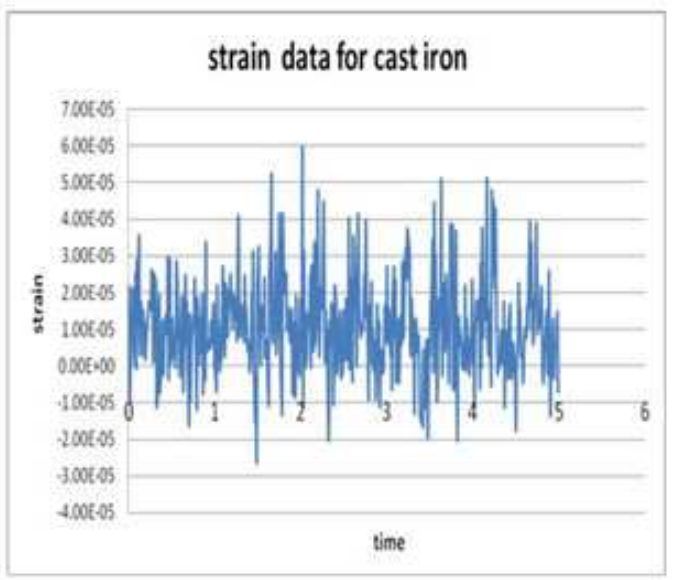

Fig6. Maximum Strain Value

This esteem is taken and contrasted and the limited component examination strain esteems. This is appeared in fig -6 . The estimation of burden in power hacksaw machine has done by utilizing the converse FEM strategy, the test top estimation of the strain was recorded by utilizing the LABVIWE programming. The greatest estimation of the 
strain happens at the most extreme power connected on the material to cut.

The most extreme esteem was taken from test vales. Limited component examination completed for hacksaw machine by considering the best possible limit conditions; the readings are taken from FEM for arrangement of burden, the exploratory and limited component readings by taking distinction of the two qualities and the mistake is determined. The base mistake has found and the particular burden is the accurate burden connected on the material to cut. The exploratory esteem is $\mathbf{5 9}$ miniaturized scale strains. Table - 6.1 demonstrates the estimation of burden.

Table-2: Estimated Load

\begin{tabular}{|c|c|c|}
\hline Load N & FEM Strain $\mu \varepsilon$ & Error \% \\
\hline 400 & 44 & 34 \\
\hline 450 & 49 & 20 \\
\hline 500 & 55 & 7.27 \\
\hline $\mathbf{5 5 0}$ & $\mathbf{6 0}$ & $\mathbf{1 . 6 6}$ \\
\hline 600 & 66 & 10.60 \\
\hline 650 & 72 & 18.055 \\
\hline 700 & 78 & 24.35 \\
\hline 750 & 83 & 28.91 \\
\hline 800 & 89 & 33.70 \\
\hline
\end{tabular}

For dynamic contextual analysis of burden estimation, the power hacksaw machine has been examined. Amid cutting task in hacksaw machine, it is hard to assess the heap on the sharp edge and the machine individuals. Along these lines, reverse limited component strategy can be utilized for estimation of burden in the event of hacksaw machine. The trial crest strain was contrasted and the limited component examination strain information. The base mistake was found and the power is evaluated.

\section{CONCLUSIONS}

It is realized that regular power hacksaw machine can be supplanted with robotized control Hacksaw machine. Mechanized power hacksaw machine gives high efficiency in brief time span in correlation with the ordinary power hacksaw machines. The significant preferred standpoint of this machine is intercession of work is diminished to greatest dimension. In this fast developing modern segment the utilization of intensity Hacksaw machine is wide, time and work assumes a noteworthy job underway procedure. This can be overwhelmed by utilizing this sort of mechanized machines which I have proposed.

\section{References}

[1] D. V. Sabariananda1, V. Siddhartha1, B. Sushil Krishnana, Design and Fabrication of Automated Hacksaw Machine, volume 3, unique issue 2, April 2014.

[2] Standard sharp edge sizes utilized in power hacksaw machines utilizing the connection http://www.planomillers.com/ - saw on August 2, 2013.

[3] Anthony Esposito 'Liquid Power with applications', sixth Edition, Pearson Education Inc. 2011.

[4] Muhammad Ali Mazidi, Janice Gillispie Mazidi, and Rolin D. McKinlay 'The 8051 Micro Controller and Embedded Systems', second Edition, Pearson Education Inc. 2008.

[5] Halil bil, reproduction of symmetrical metal cutting by limited component investigation, august 2003
[6] Cecil Reid Attaway, Am investigation of the symmetrical metal cutting procedure, December, 1968

[7] Vahid Kalhori, Modeling and Simulation of Mechanical Cutting, 2001: 28. ISSN 1402-1544

[8] David Gordon Wilson "UNDERSTANDING PEDAL POWER" ISBN: 0-86619-2689 [C] 1986, Volunteers in Technical Assistance" Technical paper 51 VITA 1600 Wilson Boulevard USA.

[9] Zoeb khan, " Design and Fabrication of Human Powered Wood Cutting machine" ,International Journal on Recent and Innovation Trends in Computing and Comm unication ISSN: 2321-8169 Volume: 3 Issue: 2 072- 074.

[10] Linxu, Weinan Bai, Jingyu Ru, Qiang Li, "Structure and Implementaion of the Reciprocating Pedal Powered Electricity Generating Device", Advanced Materials Research (Vol.282-283 (2011) pp 735-738.

[11] Chaudhary Pravinkumar k,"Understanding pedal power" ISBN: 0-86619268-9 [C] 1986, Volunteers in Technical Assistance" Technical paper 51 VITA 1600 Wilson Boulevard USA.

[12] S. G. Bahaley, Dr. A. U. Awate, S. V. Saharkar, "Execution Analysis of Pedal Powered Multipurpose Machine", International Journal of Engineering Research and Development (IJERD) (Vol.1, Issue.5,e-ISSN:22780181) (2012).

[13] Kshirsagar Prashant R,"Theoretical Analysis of MultiWay Power Hacksaw Machine" , International Journal of Research in Advent Technology, Vol.3, No.4, April 2015 E-ISSN: 2321-9637.

[14] Sreejith K. , "Exploratory Investigation of Pedal Driven Hacksaw", Research Inventy: International Journal of Engineering And Science Vol.4, Issue 7 (July 2014), PP 01-05 Issn (e): 2278-4721, Issn (p):2319-6483.

[15] Dharwa Chaitanya Kirtikumar,"designed and built up a multipurpose machine which does not require power for a few tasks like cutting, pounding", International Journal for Technological Research in Engineering (Vol.1, Issue.1, ISSN: 2347-4718) (2013).

[16] S. G. Bahaley, Dr. A. U. Awate, S. V. Saharkar, "Execution Analysis of Pedal Powered Multipurpose Machine", International Journal of Engineering Research and Development (IJERD) (Vol.1, Issue.5,e-ISSN:22780181) (2012).

[17] Linxu, Weinan Bai, Jingyu Ru,Qiang Li, "Plan and Implementaion of the Reciprocating Pedal Powered Electricity Generating Device", Advanced Materials Research (Vol.282-283 (2011) pp 735-738.

[18] Antti-jussi romppanen "Backwards load detecting strategy for finding a line load dissemination" Tampere University of innovation, 31st of October.

[19] J. F Doyle professor."Determine the effect constrain for bar and plate sort of structures exposed to transverse effects." Exp.mech,27(10), 68,1987.

[20] S. E. S. Karlsson "Examined an ID of outer auxiliary burden by estimating consonant reactions." Division of Solid Mechanics, Chalmers University of Technology, S41296 Gothenburg, Sweden.

[21] Nagraj M harihar "Backwards limited component way to deal with decide the static and dynamic powers following up on vehicle show" Mtech venture 2010.

[22] Ravinarayan R.Rao "constrain estimation on a mechanical part by opposite limited component approach "Mtech venture 2008. 